\title{
Arbuscular mycorrhizal fungal association in Asteraceae plants growing in the arid lands of Saudi Arabia
}

\author{
Partha P DHAR, Abdul A AL-QARAWI, Mohammed A U MRIDHA* \\ Plant Production Department, College of Food and Agricultural Sciences, King Saud University, Riyadh 11451, Kingdom of \\ Saudi Arabia
}

\begin{abstract}
The present research was undertaken to explor the possibility of arbuscular mycorrhizal (AM) association with Asteraceae plants in the arid lands of Saudi Arabia (Al-Ghat, Buraydah, Thumamah and Huraymila). AM fungal colonization in the roots, spore numbers in the rhizosphere soil, fungal species diversity and correlation between AM properties and soil properties were determined. The highest colonization was in Conyza bonariensis (65\%) from Al-Ghat, Anthemis cotula (52\%) from Buraydah and C. bonariensis (53\%) from Thumamah. The lowest was in Vernonia schimperi (41\%) from Al-Ghat, Pulicaria undulata (25\%) from Buraydah, Acanthospermum hispidum (34\%) from Thumamah, Asteriscus graveolens (22\%) and V. schimperi (22\%) from Huraymila. Vesicular and arbuscular colonization were also presented in all plant species examined. The number of spores were 112-207 in Al-Ghat, 113-133 in Buraydah, 87-148 in Thumamah and 107-158 in Huraymila. Funneliformis mosseae, Glomus etunicatum, G. fasciculatum and G. aggregatum were identified. Relative frequency of AM fungal species varied widely and was irrespective of location and plant species. Diversity index varied with the rhizosphere soils of different plant species at various locations. Soil properties varied with locations and no distinct correlations were observed among the soil properties, root colonization and the number of spores. The results of the present study specified the association of AM fungi in different plants of Asteraceae and its significance in the ecological functioning of annual plants in the punitive environments of the rangelands in Saudi Arabia.
\end{abstract}

Keywords: arbuscular mycorrhizal fungi; arid land; Asteraceae; biodiversity; colonization; Saudi Arabia

Citation: Partha P DHAR, Abdul A AL-QARAWI, Mohammed A U MRIDHA. 2015. Arbuscular mycorrhizal fungal association in Asteraceae plants growing in the arid lands of Saudi Arabia. Journal of Arid Land, 7(4): 676-686. doi: 10.1007/s40333-015-0081-5

Saudi Arabia occupies $80 \%$ of the Arabian Peninsula. The Peninsula consists of a central plateau, a range of deserts, ranges of mountains and dry and marshy coastlands. Saudi Arabia's geography is dominated by Arabian Desert, semi-desert and shrubland. Wadis are numerous and with no river and lake in the country. The central, eastern and northern zones of Saudi Arabia are arid and extreme arid in nature. In the arid lands, drought, salinity, and nutrient deficiency are the challenging abiotic stresses limiting the plant survival, growth, development and yielding (Kramer and Boyer, 1995). In the hinterland of Saudi Arabia, rain- fall is in the form of infrequent showers in winter. Ephemeral plants appear in winter and spring and overcome the harsh conditions to complete their life-cycle in the arid lands of Saudi Arabia. The vegetations in Saudi Arabia contain 132 families and 2,253 species among which 222 species belong to Asteraceae (Al-Farhan, 1999). These annual plants play significant roles in reducing the extent of desertification and soil erosion in the desert and dry habitats. Plants growing in these stressed conditions have different special features of adaptation through morphological, anatomical and physiological responses (Bray, 1997).

\footnotetext{
${ }^{*}$ Corresponding author: Mohammed A U MRIDHA (Email: mridha52@gmail.com) 
Arbuscular Mycorrhizal Fungi (AMF), belonging to Phylum-Glomeromycota (Redecker et al., 2013), are biotic elements in terrestrial ecosystems forming mutualistic symbiotic association with roots of the most of the terrestrial plants (Gianinazzi et al., 2010). AMF contribute to plant growth by taking up of slow releasing nutrients (Newsham et al., 1995), increasing drought tolerance (Auge, 2001; Ruiz-Lozano et al., 2001) and salinity tolerance (Evelin et al., 2009), helping in establishment and growth in harsh environments (Koske and Polson, 1984), providing protection against soil borne pathogens (Azcon-Aguilar and Barea, 1996), improving host physiological processes, plant diversity (Van der Heijden et al., 1998) etc.

Reports on the AM association in the Asteraceae plant species are available in Cuba (RodríguezRodríguez et al., 2013), India (Hemavani and Thippeswamy, 2013a), USA (Koske and Gemma, 2002; Conrad and Segraves, 2013), China (Yanfang et al., 2012) and Australia (Warcup and McGee, 1983). Herbaceous Asteraceae plants were mycorrhizal in Bhadra Wildlife sanctuary in India (Hemavani and Thippeswamy, 2013a). AMF were highly effective to enhance the establishment and growth of the halophyte Asteriscus maritimus of Asteraceae under saline conditions (Estrada et al., 2013). AMF inoculation in the soil of Calendula officinalis increased the reproductive plant parts (Zaller et al., 2011). Invasive plants of Asteraceae adopted mycorrhizal association as means of invasion (Yanfang et al., 2012). Rai and Acharya (1999) reported mycorrhizal occurrence in different Asteraceae plants growing in cultivated fields, riverbanks, wastelands and gardens. Both ectomycorrhiza and AMF were recorded in the annual and perennial herbaceous plants of Asteraceae (Warcup and McGee, 1983). However, no specific study on the mycorrhizal status and their relationship with soil physical and chemical properties was available in harsh conditions of arid habitats in Saudi Arabia. We hereby pointed out the following questions: 1) Are the annual plants of Asteraceae growing in the dry habitats of Saudi Arabia mycorrhizal? 2) What is the species composition of AMF in the harsh habitats of the study sites? 3) Are there any relationships among the soil properties and AM properties of the Asteraceae plants in the dryland ecosystems under investigation?

\section{Material and methods}

\subsection{Site selection, characterization and sample collection}

Plant species and the edaphoclimatic conditions of the study areas are presented in Table 1. Samples of Asteraceae plants were collected from $\mathrm{Al}-\mathrm{Ghat}$ and $\mathrm{Bu}-$ raydah of Al-Qassim region and Huraymila and Thumamah of Ar-Riyadh region in Saudi Arabia to study the arbuscular mycorrhizal (AM) colonization, the number of spores and the species composition of Glomeromycota.

Three replicated roots and rhizosphere soil samples were collected from $0-30 \mathrm{~cm}$ soil layer at the flowering stage of the plants in mid-January to mid-February by digging with a soil corer with utmost care to avoid the damage to the root systems. In the laboratory, the roots were separated from the soils and were preserved in 50\% alcohol for future studies after cleaning and washing. Soil samples were sieved with $2 \mathrm{~mm}$ sieves and were kept at low temperature conditions.

Table 1 Edaphoclimatic conditions and the selected plant species from different locations

\begin{tabular}{|c|c|c|c|}
\hline \multicolumn{2}{|c|}{ Location } & Edaphoclimatic conditions & \multirow{2}{*}{$\begin{array}{l}\text { Plant species } \\
\text { Asteriscus graveolens (Forssk.) Less., Calendula officinalis L., Conyza } \\
\text { bonariensis (L.) Cronquist, Koelpinia linearis Pallas, Launaea nudicau- } \\
\text { lis, (L.) Hook. f., Sonchus arvensis L., Vernonia schimperi DC }\end{array}$} \\
\hline \multirow[t]{2}{*}{ Al-Qassim } & Al-Ghat & $\begin{array}{l}\text { Semi-arid to arid, annual temperature } \\
17-33^{\circ} \mathrm{C} \text {, annual precipitation } 0.2-26.6 \mathrm{~mm}\end{array}$ & \\
\hline & Buraydah & $\begin{array}{l}\text { Semi-arid to arid, annual temperature } \\
17-33^{\circ} \mathrm{C} \text {, annual precipitation } 0.2-26.6 \mathrm{~mm}\end{array}$ & $\begin{array}{l}\text { Acanthospermum hispidum DC, Anthemis cotula L., Pulicaria undulata } \\
\text { (L.) C.A. Mey., Rhanterium epapposum Oliv, S. arvensis L. }\end{array}$ \\
\hline \multirow[b]{2}{*}{ Ar-Riyadh } & Thum & $\begin{array}{l}\text { Semi-arid to arid, annual temperature } \\
18-33^{\circ} \mathrm{C} \text {, annual precipitation } 1.2-26.6 \mathrm{~mm}\end{array}$ & $\begin{array}{l}\text { A. hispidum DC, A. cotula L., C. bonariensis (L.) Cronquist, P. undulata } \\
\text { (L.) C.A. Mey }\end{array}$ \\
\hline & Huraymila, & $\begin{array}{l}\text { Semi-arid to arid, annual temperature } \\
18-33^{\circ} \mathrm{C} \text {, annual precipitation } 1.2-26.6 \mathrm{~mm}\end{array}$ & $\begin{array}{l}\text { A. hispidum DC, A. graveolens (Forssk.) Less., C. officinalis L., C. } \\
\text { bonariensis (L.) Cronquist, K. linearis Pallas, L. nudicaulis (L.) Hook. } \\
\text { f., S. arvensis L., V. schimperi DC }\end{array}$ \\
\hline
\end{tabular}




\subsection{Root processing and assessment for my- corrhizal colonization}

Preserved roots after washing in water were stained with $0.05 \%$ trypan blue by following established method (Philips and Hayman, 1970; Koske and Gemma, 1989) with little modifications (Dhar and Mridha, 2006; Rodríguez-Rodríguez et al., 2013). Assessment of AM colonization was performed under digital computerized microscope (Model DP-72, Olympus) at 20x magnification. Data were recorded on different AMF structural variables, e.g. colonization rate of AM structures (mycelium, vesicle and arbuscule). Mycelial colonization was regarded as total root colonization. The percentage of AM structural colonization was calculated as the equation (Hemavani and Thippeswamy, 2013b) below.

Percentage of colonization $=$

$\frac{\text { Total No. of AM Positive segments }}{\text { Total No. of root segments studied }} \times 100$.

\subsection{Soil sample processing of and spore isolation}

For each sample, $100 \mathrm{~g}$ soil was processed to study the number of spores and AMF species diversity by wet sieving and decanting (Gerdemann and Nicolson, 1963) followed by centrifugation in sucrose solution with some modifications (Dhar and Mridha, 2006; Rodríguez-Rodríguez et al., 2013). The series of ASTM-60 $(250 \mu \mathrm{m})$, ASTM-270 $(53 \mu \mathrm{m})$ and ASTM-400 $(38 \mu \mathrm{m})$ sieves were used to extract the spores from soil-water suspension. Spore suspension was filtered through gridded Whatman filter paper No 1 (to facilitate the easy counting of the spores) (Dhar and Mridha, 2006). Three replications of soil subsamples were used for spore counting.

\subsection{Identification of AMF spores}

Spores were separated on the basis of morphological characteristics with stereo-binocular microscope and examined under compound microscope after mounting on the mixture of polyvinyl alcohol in lactoglycerol (PVLG) and Melzer's reagent (1:1 v/v) to identify them by following Schenck and Perez (1990), INVAM (2013), Schuessler and Walker (2010) and Redecker et al. (2013). Relative frequency of each AM fungal species (Eq. 2) and Shannon's diversity index (Hs; Eq.3).
Relative Frequency of AMF species =

$$
\frac{\text { Spore No. of an AMF species }}{\text { Total No. of AMF spores }} \times 100 \text {. }
$$

$$
\mathrm{Hs}=\frac{C}{N}\left\{(N \log 10 N)-\sum n_{i} \log 10 n_{i}\right\} .
$$

where $\mathrm{C}=3.321928$ (constant used in converting $\log _{10}$ to $\left.\log _{2}\right), \mathrm{N}$ is the total number of individual and $\mathrm{n}_{i}$ is the number of species in the " ${ }^{\text {th }}$ ' species (Simpson, 1949; Lloyd et al., 1968).

\subsection{Soil analysis}

Soil samples collected from different sites were analyzed for soil texture, $\mathrm{pH}$, available $\mathrm{N}, \mathrm{P}, \mathrm{K}$ and organic matter (OM) (Page et al., 1982).

\subsection{Statistical analysis}

Statistical software SPSS-21 was used to analyze the data for Pearson correlation and one way ANOVA for Duncan's multiple range tests (DMRT) at 0.05 significance level.

\section{Results}

\subsection{Colonization of AMF in roots}

The total mycelial, vesicular and arbuscular colonization in various locations are presented in Table 2. Variations were found in all aspect but not always agree with the percentage of infection. Significant variations were observed in respect of the mycelial, vesicular and arbuscular colonization among the individual plant species collected from various locations. The percentage of root colonization was high in Al-Ghat, medium in Buraydah and low in Huraymila and Thumamah. In Al-Ghat area, the highest mycelial colonization appeared in C. bonariensis, vesicular colonization in $K$. linearis and arbuscular colonization in L. nudicaulis. The lowest mycelial colonization was found in $V$. schimperi, vesicular colonization in $S$. arvensis and arbuscular colonization in $V$. schimperi. Variations of mycelial, vesicular and arbuscular colonizations were also observed in Buraydah. The highest mycelial colonization was found in A. cotula and the lowest was in P. undulata. Vesicular and arbuscular colonization varied significantly regardless of plant species in Thumamah mycelial. C. bonariensis had the highest colonization of mycelium, vesicles and 
Table 2 Total colonization with arbuscular mycorrhizal fungi (AMF) structures in the roots of different plant species of Asteraceae collected from different locations

\begin{tabular}{|c|c|c|c|c|}
\hline \multirow{2}{*}{ Location } & \multirow{2}{*}{ Plant species } & \multicolumn{3}{|c|}{ Total colonization $(\%)$} \\
\hline & & Mycelium & Vesicle & Arbuscule \\
\hline \multirow{7}{*}{ Al-Ghat } & A. graveolens & $54 \pm 1.52^{\mathrm{b}}$ & $46 \pm 1.11^{\mathrm{d}}$ & $64 \pm 1.05^{\mathrm{cd}}$ \\
\hline & C. officinalis & $55 \pm 1.24^{\mathrm{b}}$ & $38 \pm 1.14^{\mathrm{e}}$ & $56 \pm 2.04^{\mathrm{ef}}$ \\
\hline & C. bonariensis & $65 \pm 3.11^{\mathrm{a}}$ & $62 \pm 2.14^{\mathrm{b}}$ & $73 \pm 3.11^{\mathrm{ab}}$ \\
\hline & K. linearis & $64 \pm 2.41^{\mathrm{a}}$ & $71 \pm 1.36^{\mathrm{a}}$ & $71 \pm 2.15^{\text {bc }}$ \\
\hline & L. nudicaulis & $63 \pm 1.55^{\mathrm{a}}$ & $63 \pm 3.14^{\mathrm{b}}$ & $81 \pm 1.11^{\mathrm{a}}$ \\
\hline & S. arvensis & $44 \pm 3.11^{\mathrm{c}}$ & $35 \pm 2.13^{\mathrm{e}}$ & $59 \pm 2.13^{\mathrm{de}}$ \\
\hline & V. schimperi & $41 \pm 1.21^{\mathrm{c}}$ & $54 \pm 2.14^{\mathrm{c}}$ & $48 \pm 3.11^{\mathrm{f}}$ \\
\hline \multirow{5}{*}{ Buraydah } & A. hispidum & $45 \pm 1.45^{\mathrm{b}}$ & $25 \pm 2.14^{\mathrm{c}}$ & $45 \pm 1.02^{\mathrm{a}}$ \\
\hline & A. cotula & $52 \pm 1.36^{\mathrm{a}}$ & $25 \pm 1.31^{\mathrm{c}}$ & $32 \pm 1.32^{\mathrm{d}}$ \\
\hline & P. undulata & $25 \pm 3.24^{\mathrm{c}}$ & $34 \pm 3.15^{\mathrm{ab}}$ & $35 \pm 2.01^{\mathrm{cd}}$ \\
\hline & R. epapposum & $44 \pm 2.33^{\mathrm{b}}$ & $32 \pm 4.14^{b}$ & $32 \pm 2.31^{\mathrm{d}}$ \\
\hline & S. arvensis & $52 \pm 2.10^{\mathrm{a}}$ & $36 \pm 4.15^{\mathrm{a}}$ & $39 \pm 1.33^{\mathrm{b}}$ \\
\hline \multirow{4}{*}{ Thumamah } & A. hispidum & $34 \pm 1.03^{b}$ & $30 \pm 1.23^{\mathrm{b}}$ & $31 \pm 1.14^{\mathrm{c}}$ \\
\hline & A. cotula & $35 \pm 1.44^{\mathrm{b}}$ & $42 \pm 2.15^{\mathrm{ab}}$ & $35 \pm 3.41^{\mathrm{b}}$ \\
\hline & C. bonariensis & $53 \pm 1.31^{\mathrm{a}}$ & $46 \pm 4.31^{\mathrm{a}}$ & $49 \pm 2.01^{\mathrm{a}}$ \\
\hline & P. undulata & $35 \pm 1.21^{\mathrm{b}}$ & $25 \pm 3.1^{b}$ & $33 \pm 1.32^{b c}$ \\
\hline \multirow{8}{*}{ Huraymila } & A. hispidum & $37 \pm 1.03^{c}$ & $25 \pm 1.23$ & $39 \pm 2.14^{\mathrm{a}}$ \\
\hline & A. graveolens & $22 \pm 3.11^{\mathrm{e}}$ & $31 \pm 2.14^{\mathrm{b}}$ & $34 \pm 3.14^{\mathrm{b}}$ \\
\hline & C. officinalis & $51 \pm 3.02^{\mathrm{a}}$ & $25 \pm 2.16^{\mathrm{c}}$ & $40 \pm 1.21^{\mathrm{a}}$ \\
\hline & C. bonariensis & $47 \pm 2.01^{\mathrm{b}}$ & $43 \pm 2.61^{\mathrm{a}}$ & $38 \pm 1.03^{\mathrm{a}}$ \\
\hline & K. linearis & $38 \pm 1.03^{\mathrm{c}}$ & $42 \pm 1.06^{\mathrm{a}}$ & $27 \pm 3.02^{\mathrm{c}}$ \\
\hline & L. nudicaulis & $33 \pm 3.11^{\mathrm{d}}$ & $33 \pm 1.34^{\mathrm{b}}$ & $26 \pm 4.12^{\mathrm{c}}$ \\
\hline & S. arvensis & $37 \pm 4.12^{\mathrm{c}}$ & $25 \pm 2.11^{\mathrm{c}}$ & $39 \pm 1.42^{\mathrm{a}}$ \\
\hline & V. schimperi & $22 \pm 2.14^{\mathrm{e}}$ & $31 \pm 3.10^{\mathrm{b}}$ & $34 \pm 2.14^{\mathrm{b}}$ \\
\hline
\end{tabular}

Note: values followed by different letters indicated the significant variation as shown by DMRT $(P<0.05)$. Mean \pm standard deviation, $n=3$

arbuscules. The lowest vesicular colonization was in $P$. undulata while $A$. hispidum had the lowest mycelial and arbuscular colonizations. From Huraymila the highest mycelial colonization was in C. officinalis while the lowest was in V. schimperi. Vesicular colonization was the highest in C. bonariensis and the lowest was in A. hispidum, C. officinalis and S. arvensis. Arbuscular colonization was recorded as the highest in C. officinalis with the lowest in L. nudicaulis.

A. hispidum, C. bonariensis and S. arvens were observed in three of four locations while R. epapposum appeared in one location. A. graveolens, K. linearis, $L$. nudicaulis, S. arvensis and $V$. schimperi had higher percentage of colonization in Al-Ghat. However, they showed lower percentage of colonization in Huraymila. C. officinalis was found in Al-Ghat and Huraymila showed no significant variation in colonization like other plants species. P. undulata was found in two distinct sites. Buraydah and Thumamah showed similar root colonization percentage.

\subsection{Number of AMF spores}

The number of AMF spores of the soil samples from the different locations are stated in Fig. 1. In Al-Ghat, the maximum number of spores was found in the soil of $K$. linearis followed by $C$. bonariensis and the minimum was in $S$. arvensis. The number of spores was more or less similar in the rhizosphere soils of $A$. 
graveolens, C. officinalis, S. arvensis and V. schimperi in Al-Ghat. In Buraydah, the largest number of spores was found in A. hispidum and the smallest was in A. cotula. The number of AMF spores were almost similar in the rhizosphere soils of $P$. undulata, R. epapposum and S. arvensis from Buraydah. In Thumamah, the number of AM fungal spores were the highest in the rhizosphere soils of $P$. undulata which was followed by $C$. bonariensis and A. cotula. The lowest number of spores appeared in the soils of A. hispidum while soil sample of $P$. undulata had the highest. In Huraymila, the maximum number of spores were in the rhizosphere soils of $C$. officinalis followed by $K$. linearis and $A$. hispidum. The minimum number of spores were observed in the soils of $L$. nudicaulis.

\subsection{AM fungal diversity}

Relative frequency and species composition of AMF in the rhizosphere soil of different plant species in Al-Ghat, Buraydah, Thumamah and Huraymila are presented in Table 3. The relative frequency of AM fungal spore varied widely irrespective of locations and plant species. All soil samples showed AM fungal spores and the most of the identified spores were under genus Glomus. Identified AMF were Funneliformis mosseae (Nicolson \& Gerd.) Walker \& Schuessler, G. etunicatum Becker \& Gerd. G. fasciculatum Walker \& Koske, G. intraradices Schenck \& Sm. and G. aggregatum Schenck \& Sm. A few spores were unidentified.

Hs of AMF in the soils of different locations showed

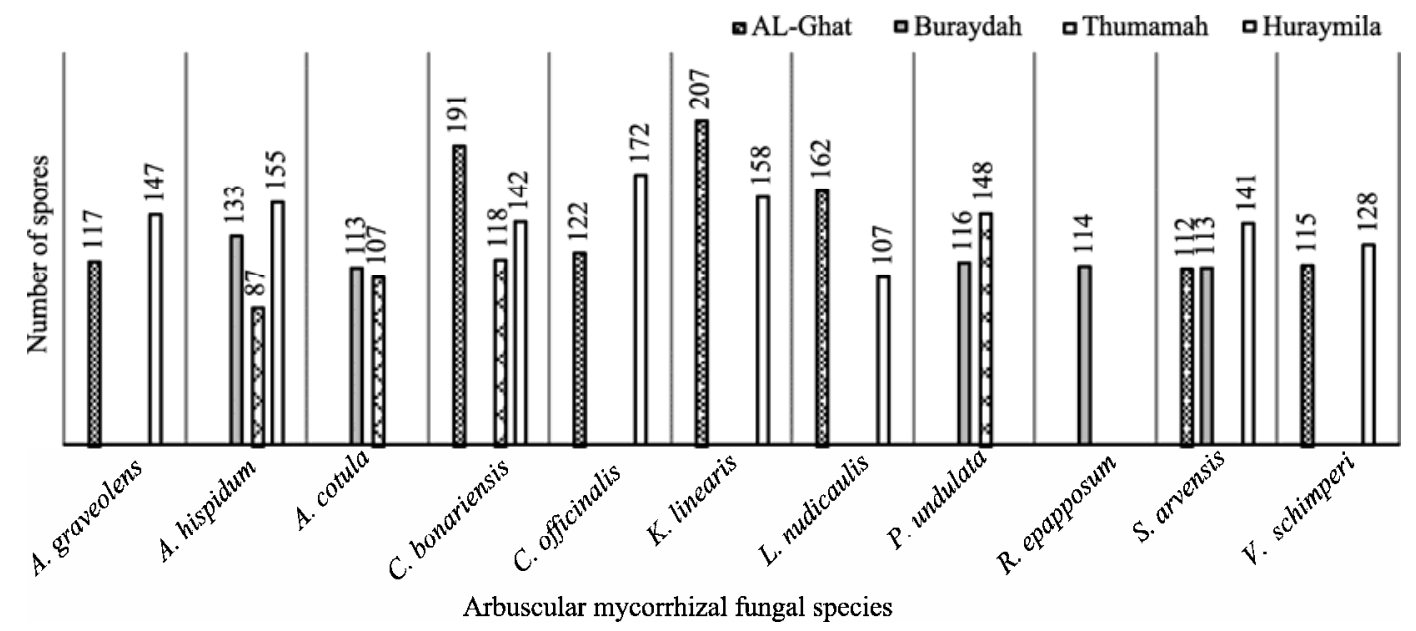

Fig. 1 Number of spores in the rhizosphere soils of different Asteraceae plants

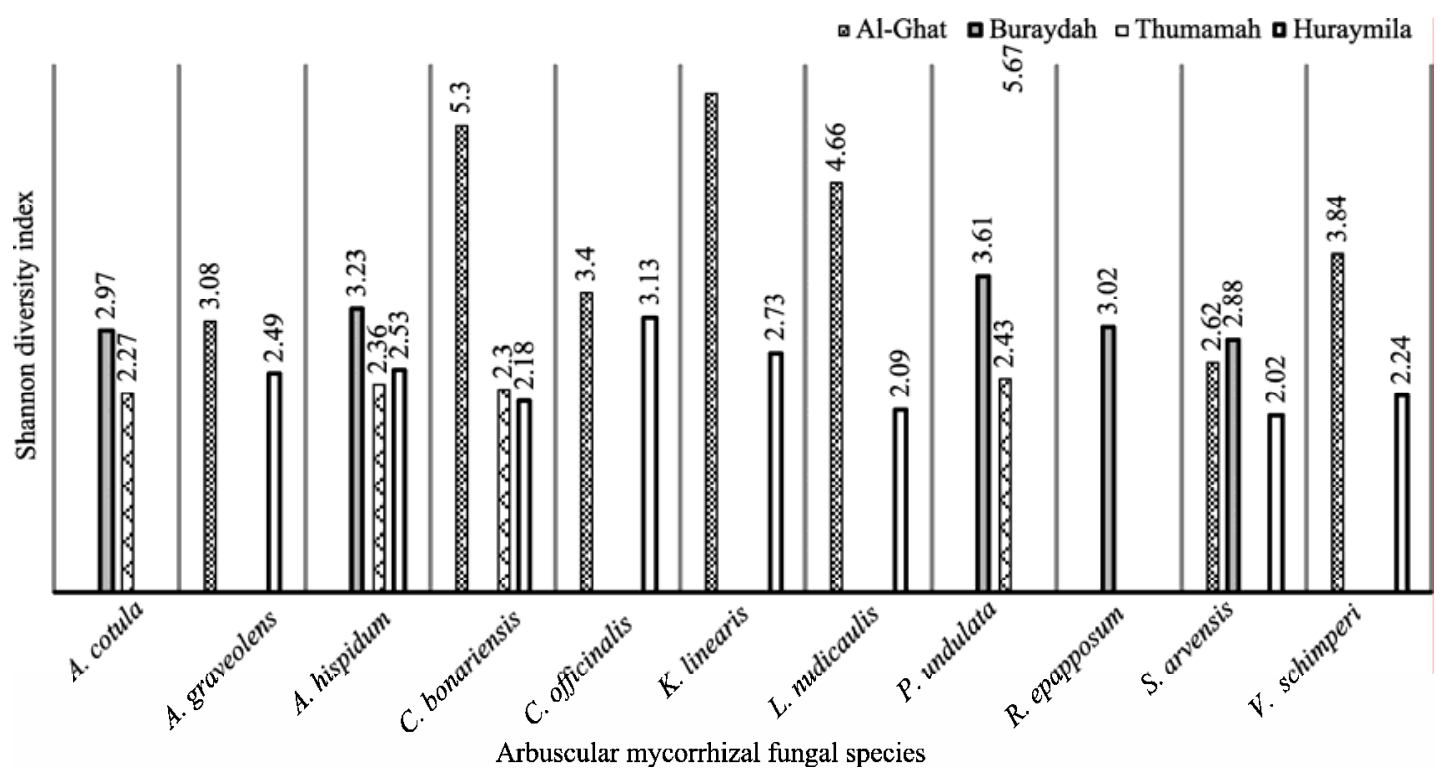

Fig. 2 Shannon Diversity Index (Hs) of AMF detected from rhizosphere soils of different Asteraceae plants 
Table 3 Frequency of AMF in the rhizosphere soils of different Asteraceae plants collected from different locations

\begin{tabular}{|c|c|c|c|c|c|c|c|}
\hline \multirow{2}{*}{ Locations } & \multirow{2}{*}{ Plant species } & \multicolumn{6}{|c|}{ Relative frequency of AMF (per $100 \mathrm{~g}$ soil) } \\
\hline & & F. mos & G. etu & G. fas & G. int & G. agg & Unid \\
\hline \multirow[t]{7}{*}{ Al-Ghat } & A. graveolens & $24 \pm 2.08^{c}$ & $28 \pm 3.05^{\mathrm{c}}$ & $19 \pm 2.52^{\mathrm{d}}$ & $16 \pm 3.46^{\mathrm{d}}$ & $00 \mathrm{~g}$ & $13 \pm 4.04$ \\
\hline & C. officinalis & $13 \pm 2.00^{\mathrm{d}}$ & $29 \pm 2.08^{b}$ & $29 \pm 3.06^{\mathrm{a}}$ & $11 \pm 1.53^{\mathrm{g}}$ & $13 \pm 3.06^{\mathrm{a}}$ & $5 \pm 4.73$ \\
\hline & C. bonaiensis & $27 \pm 1.53^{\mathrm{a}}$ & $15 \pm 1.53^{\mathrm{f}}$ & $29 \pm 1.79^{\mathrm{a}}$ & $14 \pm 3.06^{\mathrm{e}}$ & $6 \pm 5.68^{d}$ & $8 \pm 8.66$ \\
\hline & K. linearis & $11 \pm 9.29^{\mathrm{e}}$ & $15 \pm 7.80^{\mathrm{f}}$ & $30 \pm 4.16^{\mathrm{a}}$ & $18 \pm 5.29^{c}$ & $7 \pm 7.02^{\mathrm{c}}$ & $19 \pm 4.04$ \\
\hline & L. nudicaulis & $23 \pm 4.04^{\mathrm{c}}$ & $25 \pm 5.69^{d}$ & $29 \pm 5.69^{\mathrm{a}}$ & $12 \pm 4.58^{\mathrm{f}}$ & $3 \pm 4.16^{\mathrm{f}}$ & $8 \pm 2.65$ \\
\hline & S. arvensis & $13 \pm 3.51^{\mathrm{d}}$ & $33 \pm 2.52^{\mathrm{a}}$ & $20 \pm 8.23^{\mathrm{c}}$ & $20 \pm 2.52^{b}$ & $8 \pm 9.29^{b}$ & $7 \pm 3.06$ \\
\hline & V. schimperi & $26 \pm 3.61^{b}$ & $23 \pm 3.61^{\mathrm{e}}$ & $21 \pm 1.53^{b}$ & $22 \pm 2.52^{\mathrm{a}}$ & $5 \pm 5.03^{\mathrm{e}}$ & $4 \pm 2.00$ \\
\hline \multirow[t]{5}{*}{ Buraydah } & A. hispidum & $12 \pm 3.51^{\mathrm{c}}$ & $22 \pm 3.51^{\mathrm{c}}$ & $30 \pm 4.04^{\mathrm{a}}$ & $13 \pm 2.65^{d}$ & $12 \pm 3.05^{\mathrm{b}}$ & $11 \pm 5.56$ \\
\hline & A. cotula & $22 \pm 3.21^{\mathrm{a}}$ & $21 \pm 3.05^{\mathrm{c}}$ & $14 \pm 3.51^{\mathrm{d}}$ & $24 \pm 4.16^{\mathrm{a}}$ & $9 \pm 8.54^{\mathrm{c}}$ & $10 \pm 10.58$ \\
\hline & P. undulata & $14 \pm 2.65^{c}$ & $25 \pm 2.00^{\mathrm{b}}$ & $24 \pm 7.00^{b}$ & $19 \pm 5.03^{\mathrm{bc}}$ & $12 \pm 3.21^{\mathrm{b}}$ & $6 \pm 4.00$ \\
\hline & R. epapposum & $17 \pm 2.00^{\mathrm{b}}$ & $22 \pm 3.06^{\mathrm{c}}$ & $21 \pm 2.52^{\mathrm{c}}$ & $20 \pm 4.58^{b}$ & $15 \pm 3.06^{\mathrm{a}}$ & $6 \pm 5.51$ \\
\hline & S. arvensis & $17 \pm 6.56^{\mathrm{b}}$ & $28 \pm 6.03^{\mathrm{a}}$ & $19 \pm 2.52^{\mathrm{c}}$ & $17 \pm 6.11^{\mathrm{c}}$ & $7 \pm 5.86^{\mathrm{c}}$ & $13 \pm 7.55$ \\
\hline \multirow[t]{4}{*}{ Thumamah } & A. hispidum & $16 \pm 3.61^{\mathrm{b}}$ & $23 \pm 4.41^{b}$ & $31 \pm 3.06^{\mathrm{a}}$ & $14 \pm 3.00^{\mathrm{b}}$ & $12 \pm 4.51^{\mathrm{a}}$ & $5 \pm 4.59$ \\
\hline & A. cotula & $14 \pm 3.00^{\mathrm{c}}$ & $31 \pm 5.03^{\mathrm{a}}$ & $22 \pm 6.11^{\mathrm{b}}$ & $17 \pm 5.13^{\mathrm{a}}$ & $9 \pm 2.52^{b}$ & $7 \pm 7.30$ \\
\hline & C. bonaiensis & $16 \pm 3.06^{\mathrm{b}}$ & $24 \pm 2.65^{b}$ & $22 \pm 5.57^{\mathrm{b}}$ & $15 \pm 2.86^{\mathrm{b}}$ & $8 \pm 7.00^{\mathrm{b}}$ & $16 \pm 5.98$ \\
\hline & P. undulata & $25 \pm 3.21^{\mathrm{a}}$ & $26 \pm 3.21^{\mathrm{b}}$ & $15 \pm 5.03^{\mathrm{c}}$ & $17 \pm 4.04^{\mathrm{a}}$ & $8 \pm 1.00^{\mathrm{b}}$ & $8 \pm 3.05$ \\
\hline \multirow[t]{8}{*}{ Huraymila } & A. hispidum & $14 \pm 3.61^{\mathrm{e}}$ & $20 \pm 2.52^{\mathrm{e}}$ & $23 \pm 4.72^{\mathrm{c}}$ & $14 \pm 3.05^{\mathrm{de}}$ & $17 \pm 4.04^{\mathrm{a}}$ & $13 \pm 5.03$ \\
\hline & A. graveolens & $25 \pm 4.58^{\mathrm{a}}$ & $27 \pm 5.14^{c}$ & $19 \pm 2.52^{\mathrm{d}}$ & $15 \pm 6.81^{\mathrm{a}}$ & $7 \pm 6.08^{\mathrm{c}}$ & $7 \pm 1.53$ \\
\hline & C. officinalis & $21 \pm 5.03^{b}$ & $18 \pm 3.05^{\mathrm{f}}$ & $22 \pm 3.61^{\mathrm{c}}$ & $20 \pm 2.51^{b}$ & $15 \pm 1.73^{b}$ & $4 \pm 3.79$ \\
\hline & C. bonaiensis & $19 \pm 7.00^{\mathrm{c}}$ & $10 \pm 8.72^{\mathrm{g}}$ & $38 \pm 1.53^{\mathrm{a}}$ & $20 \pm 4.00^{\mathrm{b}}$ & $6 \pm 6.00^{\mathrm{cd}}$ & $7 \pm 2.08$ \\
\hline & K. linearis & $7 \pm 6.11^{\mathrm{f}}$ & $22 \pm 7.02^{d}$ & $22 \pm 5.68^{c}$ & $29 \pm 2.65^{\mathrm{a}}$ & $18 \pm 8.19^{\mathrm{a}}$ & $3 \pm 2.65$ \\
\hline & L. nudicaulis & $16 \pm 4.73^{\mathrm{d}}$ & $38 \pm 4.04^{\mathrm{b}}$ & $12 \pm 4.16^{\mathrm{e}}$ & $17 \pm 2.51^{\mathrm{c}}$ & $5 \pm 5.51^{\mathrm{d}}$ & $12 \pm 3.51$ \\
\hline & S. arvensis & $20 \pm 3.51^{\mathrm{bc}}$ & $46 \pm 5.03^{\mathrm{a}}$ & $25 \pm 1.73^{b}$ & $4 \pm 3.61^{\mathrm{f}}$ & $1 \pm 2.31^{\mathrm{e}}$ & $13 \pm 5.57$ \\
\hline & V. schimperi & $23 \pm 5.86^{\mathrm{a}}$ & $23 \pm 2.01^{\mathrm{d}}$ & $23 \pm 1.93^{\mathrm{c}}$ & $13 \pm 3.58^{\mathrm{d}}$ & $7 \pm 6.11^{\mathrm{cd}}$ & $10 \pm 7.55$ \\
\hline
\end{tabular}

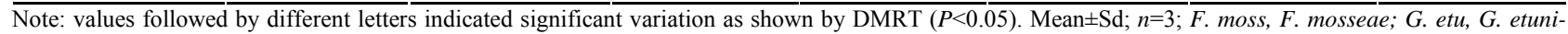
catum; G. fas, G. fasciculatum; G. int, G. intraradices; G. agg, G. aggregatum; Unid, Unidentified.

wide variations (Fig. 2). The highest Hs was calculated from the rhizosphere soils of $K$. linearis and the lowest was in the soils of S. arvensis in Al-Ghat. In Buraydah the highest and the lowest Hs were from the soil of $P$. undulata and S. arvensis, respectively. The highest $\mathrm{Hs}$ was recorded in the soils of $P$. undulata in Thumamah. The lowest was in the soils of A. cotula. In Huraymila, C. officinalis showed the highest Hs, which was followed by $K$. linearis, A. hispidum and $A$. graveolens, and the lowest was in the soils of $S$. arvensis.

\subsection{Soil properties}

The properties of rhizosphere soil of different Asteraceae plants from different locations are presented in Table 4. Physical and chemical properties of the soils collected from Al-Ghat and Huraymila were comparable. Soil textures were sandy in Buraydah and Thumamah and sandy loam in Al-Ghat and Huryamila. The range of soil $\mathrm{pH}$ was not varied widely in the most of the soil samples studied, but other soil properties varied widely irrespective of plant species and locations. $\mathrm{N}, \mathrm{P}, \mathrm{K}$ and $\mathrm{OM}$ were almost similar in Al-Ghat and Huraymila. However, the values of these soil properties were low in Buraydah and Thumamah.

\subsection{Relationships of soil properties with AMF colonization and the number of spores}

No definite and distinct correlation was observed between the soil parameters and AM properties (Table 5). Correlation between AM colonization and soil $\mathrm{pH}$ was significant and positive in Buraydah, negative in 
Table 4 Soil properties of rhizosphere soils of different Asteraceae plants from different locations

\begin{tabular}{|c|c|c|c|c|c|c|c|}
\hline \multirow{2}{*}{ Location } & \multirow{2}{*}{ Plant species } & \multirow{2}{*}{ Soil texture } & \multicolumn{5}{|c|}{ Soil Property } \\
\hline & & & $\mathrm{pH}$ & $\mathrm{N}(\mathrm{mg} / \mathrm{kg})$ & $\mathrm{P}(\mathrm{mg} / \mathrm{kg})$ & $\mathrm{K}(\mathrm{meq} / \mathrm{L})$ & OM (\%) \\
\hline \multirow{7}{*}{ Al-Ghat } & A. graveolens & Sandy loam & $7.77 \pm 0.04 *$ & $346.33 \pm 1.52$ & $54.00 \pm 1.00$ & $0.19 \pm 0.005$ & $0.51 \pm 0.01$ \\
\hline & C. officinalis & Sandy & $7.85 \pm 0.02$ & $212.00 \pm 3.00$ & $37.33 \pm 1.15$ & $0.15 \pm 0.010$ & $0.07 \pm 0.01$ \\
\hline & C. bonariensis & Sandy loam & $7.82 \pm 0.01$ & $376.33 \pm 2.08$ & $50.33 \pm 1.52$ & $0.32 \pm 0.006$ & $0.14 \pm 0.006$ \\
\hline & K. linearis & Sandy loam & $7.82 \pm 0.005$ & $415.00 \pm 2.00$ & $47.33 \pm 1.15$ & $0.31 \pm 0.02$ & $0.47 \pm 0.01$ \\
\hline & L. nudicaulis & Sandy loam & $7.61 \pm 0.01$ & $419.33 \pm 1.15$ & $53.67 \pm 1.53$ & $0.50 \pm 0.01$ & $0.44 \pm 0.01$ \\
\hline & S. arvensis & Sandy loam & $7.55 \pm 0.02$ & $433.00 \pm 1.73$ & $50.67 \pm 1.52$ & $0.76 \pm 0.011$ & $0.51 \pm 0.006$ \\
\hline & V. schimperi & Sandy loam & $7.61 \pm 0.01$ & $416.33 \pm 1.52$ & $49.00 \pm 2.00$ & $0.57 \pm 0.032$ & $0.44 \pm 0.006$ \\
\hline \multirow{5}{*}{ Buraydah } & A. hispidum & Sandy & $8.00 \pm 0.01$ & $214.00 \pm 2.00$ & $42.33 \pm 1.52$ & $0.18 \pm 0.01$ & $0.11 \pm 0.01$ \\
\hline & A. cotula & Sandy & $8.05 \pm 0.01$ & $213.00 \pm 2.65$ & $37.67 \pm 0.57$ & $0.11 \pm 0.005$ & $0.1 \pm 0.006$ \\
\hline & P. undulata & Sandy & $7.63 \pm 0.03$ & $220.33 \pm 1.15$ & $41.67 \pm 1.52$ & $0.45 \pm 0.02$ & $0.14 \pm 0.02$ \\
\hline & R. epapposum & Sandy & $8.14 \pm 0.02$ & $218.00 \pm 2.00$ & $42.66 \pm 1.53$ & $0.37 \pm 0.01$ & $0.15 \pm 0.01$ \\
\hline & S. arvensis & Sandy & $8.01 \pm 0.03$ & $224.33 \pm 2.08$ & $43.00 \pm 2.00$ & $0.44 \pm 0.01$ & $0.10 \pm 0.01$ \\
\hline \multirow{4}{*}{ Thumamah } & A. hispidum & Sandy & $8.16 \pm 0.02$ & $209.00 \pm 4.14$ & $36.00 \pm 2.00$ & $0.12 \pm 0.005$ & $0.07 \pm 0.005$ \\
\hline & A. cotula & Sandy & $8.06 \pm 0.07$ & $193.67 \pm 6.51$ & $42.00 \pm 1.75$ & $0.40 \pm 0.015$ & $0.04 \pm 0.005$ \\
\hline & C. bonariensis & Sandy & $7.87 \pm 0.02$ & $184.00 \pm 5.57$ & $41.33 \pm 1.15$ & $0.51 \pm 0.01$ & $0.03 \pm 0.01$ \\
\hline & P. undulata & Sandy & $7.96 \pm 0.07$ & $197.00 \pm 4.50$ & $33.33 \pm 1.52$ & $0.53 \pm 0.02$ & $0.05 \pm 0.01$ \\
\hline \multirow{8}{*}{ Huraymila } & A. hispidum & Sandy loam & $7.81 \pm 0.02$ & $212.33 \pm 2.08$ & $38.67 \pm 1.52$ & $0.44 \pm .03$ & $0.04 \pm 0.001$ \\
\hline & A. graveolens & Sandy loam & $7.72 \pm 0.01$ & $460.33 \pm 6.11$ & $56.33 \pm 2.08$ & $0.65 \pm 0.02$ & $0.42 \pm 0.015$ \\
\hline & C. officinalis & Sandy loam & $7.72 \pm 0.01$ & $460.67 \pm 0.57$ & $53.00 \pm 2.00$ & $0.61 \pm 0.015$ & $0.45 \pm 0.006$ \\
\hline & C. bonariensis & Sandy loam & $7.54 \pm 0.02$ & $434.33 \pm 1.15$ & $54.67 \pm 3.21$ & $0.87 \pm 0.02$ & $0.44 \pm 0.015$ \\
\hline & K. linearis & Sandy loam & $7.71 \pm 0.01$ & $423.67 \pm 1.53$ & $53.00 \pm 2.00$ & $0.47 \pm 0.01$ & $0.47 \pm 0.015$ \\
\hline & L. nudicaulis & Sandy loam & $7.65 \pm 0.015$ & $431.67 \pm 2.52$ & $53.00 \pm 2.64$ & $0.69 \pm 0.02$ & $0.51 \pm 0.01$ \\
\hline & S. arvensis & Sandy loam & $7.65 \pm 0.025$ & $434.67 \pm 1.53$ & $52.67 \pm 1.52$ & $0.43 \pm 0.006$ & $0.49 \pm 0.01$ \\
\hline & V.schimperi & Sandy loam & $7.66 \pm 0.025$ & $432.33 \pm 2.08$ & $51.33 \pm 2.51$ & $0.44 \pm 0.005$ & $0.53 \pm 0.011$ \\
\hline
\end{tabular}

$\overline{\text { Note: mean } \pm \mathrm{SD} ; \mathrm{N}}, \overline{\text { Nitrogen; } \mathrm{P} \text {, phosphorus; K, Potassium }} \overline{\text { OM, Organic matter. }}$

Table 5 Coefficient of correlation between the soil properties and AM properties of Asteraceae plants growing in the various locations of arid habitats in Saudi Arabia

\begin{tabular}{lllcccc}
\hline \multicolumn{1}{c}{ Location } & & $\mathrm{pH}$ & $\mathrm{N}$ & $\mathrm{P}$ & $\mathrm{K}$ & $\mathrm{OM}$ \\
\hline Al-Ghat & AM Colonization & 0.140 & 0.264 & 0.280 & -0.075 & -0.194 \\
& Spore Number & $0.603^{*}$ & -0.101 & 0.330 & $-0.530^{* *}$ & -0.322 \\
Buraydah & AM Colonization & $0.856^{*}$ & -0.158 & -0.202 & -0.483 & -0.298 \\
& Spore Number & -0.022 & -0.374 & -0.168 & -0.388 & -0.282 \\
\multirow{3}{*}{ Thumamah } & AM Colonization & $-0.697^{* *}$ & -0.530 & 0.490 & 0.450 & $-0.750^{*}$ \\
& Spore Number & $-0.578^{* *}$ & -0.365 & -0.370 & $0.820^{*}$ & -0.340 \\
& AMraymila & 0.450 & -0.260 & -0.230 & 0.230 & -0.340 \\
& AM Colonization & 0.400 & -0.100 & -0.090 & -0.150 & -0.300 \\
\hline
\end{tabular}

Note: "and " indicate the significance at 0.05 and 0.01 level respectively.

Thumamah and not significant in Al-Ghat and Huraymila. Mostly negative correlations were observed between AM colonization and spore numbers with other soil properties (N, P, K and OM) studied in the present programme.

\section{Discussion and conclusions}

This study confirmed the occurrence of arbuscular mycorhizal colonization in the plants of Asteraceae 
family growing in the arid lands of Saudi Arabia. Presence of AMF structures i.e. running aseptate mycelium, vesicles and arbuscules in the cells of cortical zone confirms the mycorrhizal association of AM fungal symbionts. All the plants of 11 Asteraceae species were mycorrhizal. Mycorrhizal occurrence which was previously reported in the genera of Asteraceae plants studied in the present programme (Johnson-Green et al., 1995; Shi et al., 2006; Wang and Qiu, 2006; Shah et al., 2008; Al-Qarawi et al., 2009; Estrada et al., 2013; Hemavani and Thippeswamy, 2013a). In fact, Asteraceae is a highly mycotrophic family of which 233 species were studied and were identified as arbuscular mycorrhizal (Wang and Qiu, 2006; Rodríguez-Rodríguez et al., 2013). The AMF structures in the agricultural, flowering, medicinal and ephemeral plants of Asteraceae family were reported previously in habitats of different countries including arid land and desert ecosystems (Rai and Acharya, 1999; O'Connor et al., 2001; Shi et al., 2006; Kumar et al., 2012; Zhang et al., 2012; Hemavani and Thippeswamy, 2013a). The occurrence of Mycorrhizal of Asteraceae herbs in Australian desert (Warcup and McGee, 1983) was in consistence with our findings. The occurrence of Arbuscular was similar among sites that tended to be low or medium. Low diversity of plants and harsh climatic conditions were associated to low colonization percentages. Mycorrhizal association in the Asteraceae plants was found as arbusular type (Wang and Qiu, 2006). The occurrences of both ectomycorrhizal and arbuscular mycorrhizal were reported (Warcup and McGee, 1983). Mycorrhizas in the roots of Asteraceae plants under the study were of Arum type. No Paris type of mycorrhiza was observed. This results corroborates with the observations of Smith and Smith (1997) and Shah et al. (2008). However, Koske and Gemma (2002) observed Paris type of mycorrhizae in the roots of Hawaiian Asteraceae plants in a tropical alpine habitat and co-occurrence of Arum and Paris type of AM were observed by Kubota et al. (2005) from Japan and Rodríguez-Rodríguez et al. (2013) from Cuba.

Irregular distribution of annual ephemerals in the degraded arid lands of Saudi Arabia had little effect on the AM colonization irrespective of the plant species and locations. Significant and non-significant variations in root colonization of common plant species in different locations revealed elastic relationships among plant species, AM fungal communities and edapho-climatic conditions of plant-growing sites. Fibrous and delicate roots of ephemeral plants in the desert ecosystems are suitable to be colonized by AMF (Zhang et al., 2012) as AM fungal partners prefer colonizing newly-grown roots (Allen, 2001). Our findings of $\mathrm{AM}$ colonization and intensity of $\mathrm{AM}$ structural colonization in the soft, delicate and newly grown roots of plants species of Asteraceae in the study are in favour of Zhang et al. (2012) and Allen (2001). However, the percentages of colonization of mycelium, vesicles and arbuscules were variable in different plants which were consistent with the earlier findings (Zhang et al., 2012). Significant differences in AM structural colonization $(P<0.05)$ irrespective of location and plant species might be due to the phonological effects of the plant species. Occurrence of AM colonization in the flowering stage of the studied plants was consistent with the findings of Zhang et al. (2012). Higher colonization rate and the growth of AMF during the reproductive stage might be the consequence of additional carbohydrate allocation to the symbionts (Grigera et al., 2007; Zhang et al., 2012). Varied AM colonizations were described by the previous researchers (Rai and Acharya, 1999; O’Connor et al., 2001; Shi et al., 2006; Kumar et al., 2012; Zhang et al., 2012; Hemavani and Thippeswamy, 2013a). The growth and the development of the host plants and AMF might also affect the variation of AMF structural colonization and sporulation of the fungal symbionts (Kumar et al., 2012). Our findings of AM colonization in A. graveolens were strongly supported by the high AM dependency, enhanced establishment, survival and improved growth of $A$. maritimus, a different species of the genus Asteriscus, in the saline habitats (Estrada et al., 2013). AM colonization in different plants in our present program corroborates with the studies of other researchers. For example, A. hispidum (Harikumar et al., 2014), C. bonariensis (Hemavani and Thippeswamy, 2013a), $K$. 
linearis (Rai and Acharya, 1999; Shi et al., 2006), Pulicaria crispa (Harikumar et al., 2014) and S. arvensis (Johnson-Green et al., 1995) were recorded being colonized by AMF. Vegetative and reproductive growth promotion occurred due to AMF inoculation in A. cotula (Shah et al., 2008). AM colonization in the perennial ephemeral $R$. epapposum in the study was justified by the findings of Al-Qarawi et al., (2009). Different ephemeral annual plants together with Asteraceae family dominated arid land ecosystems in the short period of spring season. These herbaceous annual plants grow well in barren, dry and turbulent environments. AM colonization in the annual ephemeral plants was important from the ecological point of view, which suggested that different Asteraceae plants growing in the Saudi Arabian arid habitats adopted mutual relationships with mycorrhizal fungi for their nutrient acquisition, survival and growth in the short duration of spring season to complete their life cycle before the summer.

Significant variation in the number of AMF spores, fungal diversity in rhizosphere of the Asteraceae plants growing in the dry lands of Saudi Arabia upholds the report of Shi et al. (2006). The dominance of Glomus in the arid land ecosystems was firmly supported by the studies of the other researchers (Lamont, 1982; Pande and Tarafdar, 2004). Significant differences in the relative frequency and diversity of AM fungal species might be used by the host species (Kumar et al., 2012). The similarity of AM fungal communities and the difference of the number of the spores irrespective of plant species and sites indicated the ratings of affinity between the plants and AM fungal species.

Diverse factors, e.g., soil texture, temperature and $\mathrm{pH}$, might be responsible for the formation and the variation in the percentage of colonization and functioning of mycorrhizas (Abbott and Robson, 1991). The distinct response of AMF to soil $\mathrm{pH}$ can be endorsed to the species and strains of native AM flora (Robson and Abbott, 1989). Changes of soil pH due to the host interaction might cause the distinctive response of mycorrhizal colonization. No significant correlation existed among soil $\mathrm{pH}, \mathrm{AM}$ colonization and the number of spores in the study, which was in favor of the conclusion of Ghorbani et al. (2012). However, a positive correlation between soil $\mathrm{pH}$ and root colonization or spore production could be established whenever necessary (Porter et al., 1987; Johnson et al., 1991). Irregular correlation between soil physical and chemical properties were found with AMF recorded AM properties and AM fungal diversity in the dry land ecosystems reflected the independent nutritional relationships among the plant species and AMF irrespective of varied edapho-climatic conditions (Ghorbani et al., 2012) in Saudi Arabia.

It is important to explore the extent to which Asteraceae plants in the Saudi Arabian arid lands are dependent on the mycorrhizal association. Nonexistence of AMF propagules in the plant growing sites may be critical to the highly AM dependent plants in these abiotically stressed habitats. Estimation of AM fungal inoculum colonization in the Asteraceae plant growing soils might be important to understand the survival and nutritional acquisition of the naturally growing annual plants of Asteraceae family under the harsh conditions in the arid lands of Saudi Arabia. The results obtained from the present study on mycorrhizal status and biodiversity of AMF indicated the significance of AMF in persistence and nutritive achievement of Asteraceae plants growing in the arid land ecosystems of Saudi Arabia.

\section{Acknowledgment}

This research was financially supported by the Deanship of Scientific Research, College of Food and Agriculture, King Saud University, Saudi Arabia.

\section{References}

Abbott L K, Robson A D. 1991. Factors influencing the formation of arbuscular mycorrhiza. Agriculture, Ecosystem and Environment, 35: $121-150$.

Al-Farhan A H. 1999. A phytogeographical analysis of the floristic elements in Saudi Arabia. Pakistan Journal of Biological Sciences, 2: $702-711$.

Allen M F. 2001. Modeling arbuscular mycorrhizal infection: is \% infection an appropriate variable? Mycorrhiza, 10: 255-258.

Al-Qarawi A A, Abdel-Fattah G M, Rowaily S L, et al. 2009. Effect of arbuscular mycorrhizal (AM) fungi on some range plants in Thumama, in Riyadh region, Saudi Arabia. Journal of King Saud University (Agricultural Science), 21: 67-86.

Auge R M. 2001. Water relations, drought and VA mycorrhizal sym- 
biosis. Mycorrhiza, 11: 3-42.

Azcón-Aguilar C, Barea J M. 1996. Arbuscular mycorrhizas and biological control of soil-borne plant pathogens: an overview of the mechanisms involved. Mycorrhiza, 6: 457-464.

Bray E A. 1997. Plant responses to water deficit. Trends in Plant Science, 2: $48-54$.

Conrad A O, Segraves K A. 2013. Mycorrhizal colonization of Palafoxia feayi (Asteraceae) in a pyrogenic ecosystem. Mycorrhiza, 23: 243-249.

Dhar P P, Mridha M A U. 2006. Biodiversity of arbuscular mycorrhizal fungi in different trees of Madhupur forest, Bangladesh. Journal of Forestry Research, 17: 201-205.

Estrada B, Aroca R, Azcon-Aguilar C, et al. 2013. Importance of native arbuscular mycorrhizal inoculation in the halophyte Asteriscus maritimus for successful establishment and growth under saline conditions. Plant and Soil, 370: 175-185.

Evelin H, Kapoor R, Giri B. 2009. Arbuscular mycorrhizal fungi in alleviation of salt stress: a review. Annals of Botany, 104: 1236-1280

Gerdemann J W, Nicolson T H. 1963. Spores of mycorrhizal Endogone extracted from soil by wet sieving and decanting. Transaction of British Mycological Society, 46: 235-244.

Ghorbani M, Khara J, Abaspoor N. 2012. Vesicular-arbuscular mycorrhizal symbioses in 7 plants and its relationship with soil factors and seasons. International Research Journal of Applied and Basic Sciences, 3: 2381-2386.

Gianinazzi S, Gollotte A, Binet M N, et al., 2010. Agroecology: The key role of arbuscular mycorrhizas in ecosystem services. Mycorrhiza, 20: 519-530.

Grigera M S, Drijber R A, Wienhold B J. 2007. Increased abundance of arbuscular mycorrhizal fungi in soil coincides with the reproductive stages of maize. Soil Biology and Biochemistry, 39: 1401-1409.

Harikumar V S, Blaszkowski J, Medhanie G, et al. 2014. Arbuscular mycorrhizal fungi colonizing the plant communities in Eritrea, Northeast Africa. Applied Ecology and Environmental Research, 13: 193-203.

Hemavani C, Thippeswamy B. 2013a. Arbuscular mycorrhizal fungi associated with some plants of Asteraceae in Bhadra wildlife sanctuary. International Journal of Plant, Animal and Environmental Sciences, 3: 106-110.

Hemavani C, Thippeswamy B. 2013b. Association of arbuscular mycorrhizal fungi in herbaceous plants of Bhadra Wildlife Sanctuary. International Journal of Research in Botany, 3: 10-12.

INVAM 2013. International culture collection of (vesicular) arbuscular mycorrhizal fungi. [2013-10-05] http://invam.wvu.edu.

Johnson N C, Zak D R, Tilman D, et al. 1991. Dynamics of vesicular-arbuscular mycorrhizae during old field succession. Oecologia, 86: 349-358.

Johnson-Green P C, Kenkel N C, Booth T. 1995. The distribution and phenology of arbuscular mycorrhizae along an inland salinity gradient. Canadian Journal of Botany, 73: 1318-1327.

Koske R E, Polson W R. 1984. Are VA mycorrhizae required for sand dune stabilization? Bioscience, 34: 420-424.

Koske R E, Gemma J N. 1989. A modified procedure for staining roots to detect VA mycorrhizas. Mycological Research, 92: 486-505.

Koske R E, Gemma J N. 2002. Mycorrhizal status of two Hawaiian plant species (Asteraceae) in a tropical alpine habitat: the threatened Haleakala silversword (Argyroxiphium sandwicense subsp. macrocephalum) and the endemic Dubautia menziesii. Pacific Science, 56: 423-430.

Kramer P J, Boyer J S. 1995. Water Relations of Plants and Soils. San Diego: Academic Press.

Kubota M, McGonigle T P, Hyakumachi M. 2005. Co-occurrence of Arum and Paris type morphologies of arbuscular mycorrhizae in cucumber and tomato. Mycorrhiza, 15: 73-77.

Kumar A, Bhatti S K, Aggarwal A. 2012. Biodiversity of endophytic mycorrhiza in some ornamental flowering plants of Solan, Himachal Pradesh. Biological Forum-An International Journal, 4: 45-51.

Lamont B. 1982. Mechanisms for enhancing nutrient uptake in plants, with particular reference to Mediterranean South Africa and Western Australia. Botanical Review, 48: 597-689.

Lloyd H, Zar K H, Karr J R. 1968. On the calculation of information-theoretical measures of diversity. The American Midland Naturalist Journal, 79: 257-272.

Nelson D W, Sommers L E. 1996. Total carbon, organic carbon, and organic matter. In: Sparks D L, Page A L, Helmke P A, et al. Methods of soil analysis. Part 3, 3ed. Chemical Methods. SSSA and ASA, Madison, WI. USA, 961-1010.

O’Connor P J, Smith S E, Smith F A. 2001. Arbuscular mycorrhizal associations in the southern Simpson Desert. Australian Journal of Botany, 49: 493-499.

Page A L, Miller R H, Keeney D R. 1982. Methods of Soil Analysis. Part 2: Chemical and Microbiological Properties ( $2^{\text {nd }}$ ed.). Madison, WI: Agronomy Society of America.

Pande M, Tarafdar J C. 2004. Arbuscular mycorrhizal fungal diversity in neem-based agroforestry systems in Rajasthan. Applied Soil Ecology, 26: 233-241.

Philips J M, Hayman D S. 1970. Improved procedures for clearing roots and staining parasitic and vesicular arbuscular mycorrhizal fungi for rapid assessment for infection. Transaction of British Mycological Society, 55: 158-161.

Porter W M, Robson A D, Abbott L K. 1987. Field survey of the distribution of vesicular-arbuscular mycorrhizal fungi in relation to soil pH. Journal of Applied Ecology, 24: 659-662.

Rai M, Acharya D. 1999. Diversity of arbuscular mycorrhizae in naturally growing plants of family Asteraceae in India. Compositae Newsletter, 34: 44-49.

Redecker D, Schuessler A, Stockinger H, et al. 2013. An evidence-based consensus for the classification of arbuscular mycorrhizal fungi (Glomeromycota). Mycorrhiza, 23: 515-531.

Robson A D, Abbott L K. 1989. The Effect of Soil Acidity on Microbial Activity in Soils. In: Robson A D. Soil Acidity and Plant Growth. Sydney: Academic Press, 139-165.

Rodríguez-Rodríguez R M, Herrera P, Furrazola E. 2013. Arbuscular mycorrhizal colonization in Asteraceae from white sand savannas, in Pinar del Río, Cuba. Biota Neotropica, 13: 136-140.

Ruiz-Lozano M J, Collados C, Barea J M, et al. 2001. Arbuscular mycorrhizal symbiosis can alleviate drought-induced nodule senescence 
in soybean plants. New Phytologist, 151: 493-502.

Schuessler A, Walker C. 2010. The Glomeromycota: a species list with new families and new genera, Edinburgh \& Kew, UK: The Royal Botanic Garden; Munich, Germany: Botanische Staatssammlung Munich; Oregon, USA: Oregon State University. [2013-11-05]. http://www.amf-phylogeny.com.

Schenck N C, Perez Y. 1990. Manual for identification of VA mycorrhizal fungi. Gainesville: Synergistic Publications.

Shah M A, Reshi Z, Rashid I. 2008. Mycorrhizal source and neighbour identity differently influence Anthemis cotula L. invasion in the Kashmir Himalaya, India. Applied Soil Ecology, 40: 330-337.

Shi Z Y, Feng G, Christie P, et al. 2006. Arbuscular mycorrhizal status of spring ephemerals in the desert ecosystem of Junggar Basin, China. Mycorrhiza, 16: 269-275.

Simpson E H. 1949. Measurement of diversity. Nature, 163: 688.

Smith F A, Smith S E. 1997. Structural diversity in (vesicular)-arbuscular mycorrhizal symbioses. New Phytologist, 137: 373-388.
Van der Heijden M G A, Klironomos J N, Ursic M, et al. 1998. Mycorrhizal fungal diversity determines plant biodiversity, ecosystem variability and productivity. Nature, 396: 69-72.

Wang B, Qiu Y L. 2006. Phylogenetic distribution and evolution of mycorrhizas in land plants. Mycorrhiza, 16: 299-363.

Warcup J H, McGee P A. 1983.The mycorrhizal association of Australian Asteraceae. New Phytologist, 95: 667-672.

Yanfang B, Min L, Shaoxia G. 2012. Development status of arbuscular mycorrhizal fungi associated with invasive plant Coreopsis grandiflora Hogg. African Journal of Microbiology Research, 6: 2779-2784

Zaller J G, Saccani F, Frank T. 2011. Effects of earthworms and mycorrhizal fungi on the growth of the medicinal herb Calendula officinalis (Asteraceae). Plant, Soil and Environment, 57: 499-504.

Zhang T, Tian C Y, Sun Y, et al. 2012. Dynamics of arbuscular mycorrhizal fungi associated with desert ephemeral plants in Gurbantunggut desert. Journal of Arid Land, 4: 43-51. 